\title{
The Relationship between Coping Skills with Social Maturity and Adjustment of Female First Graders in High School: A Case Study in Iran
}

\author{
Hanie Sadat Sadeghi ${ }^{1} \&$ Mojgan Niknam ${ }^{2}$ \\ ${ }^{1}$ Social Science Department, Azad University of Science and Research Units, Khorasan Razavi Branch, Iran \\ ${ }^{2}$ Faculty of Islamic Azad University of Roudehen, Roudehen, Tehran, Iran \\ Correspondence: Mojgan Nicknam, Department Of Counseling, Islamic Azad University, Roudehen Branch; \\ Young Researchers Club, Roudehen, Iran. E-mail: nicknam.mojgan@gmail.com
}

\author{
Received: September 3, 2015 Accepted: October 11, 2015 Online Published: October 26, 2015 \\ doi:10.5539/ass.v11n25p144 URL: http://dx.doi.org/10.5539/ass.v11n25p144
}

\begin{abstract}
The present study aims to evaluate the relationship between coping skills with social maturity and adjustment in female first graders of high school in district 7 of Tehran city. The present study is a correlational based study including 370 female students selected by multi stage random sampling method. This study applies Lazarus coping skills, social maturity scale of Vineland and Bell adjustment. The results of regression analysis show that coping skills predicts social maturity and adjustment. There is a positive and significant relation between coping skills (problem-focused, emotion-focused) with social maturity and adjustment.
\end{abstract}

Keywords: coping skills, social maturity, adjustment, female first graders

\section{Introduction}

Adolescence is a period between childhood and adulthood. Hall (1916) states that adolescence is an important transitional period in human life and an adolescent feels a lot of diversified emotions. This period in life makes adolescents oscillate between contradictory tendencies. Exuberant gaiety and euphoria replace with depressive gloom rapidly (Shoarinejad, 2009). The changes rose based on mutual interactions with other people, social conditions and organizing can be called social maturity. In other words, the changes and progresses include those from birth to death in social behavior, feelings, tendencies, and values. The measurement criteria of social maturity are adjustment with others. Social maturity is effective not only on adjustment with others; it is also effective on academic success, job progress, spouse selection and marital life satisfaction and improvement of social dignity (Lotfabadi, 2011). In other words, social maturity is called learning form relying upon adjustment with society and cultural environment. A child can collaborate with others and promotes its ability regarding self-expression and becomes to defend its benefits as a definite person (Rahnama, 2001).

According to Karen Horney, adjustment of normal behavior or non-adjustment is dependent upon the relationship of parents and children. If a person feels love, security then he/she can grow as normal. If a person is loved, tolerates many problems in future. Insecurity leads to resorting to the methods increasing internal distress (Panahi, 2014). Regarding adjustment and non-adjustment, McDonald believes that a person is adjusted as he learns to respond with environment.

In recent years, considering coping skills in social maturity and adjustment has received much attention and it is shown that using effective coping skills plays an important role in social maturity and adjustment (Mousavi et al., 2011). Coping skills refers to the methods to deal with issues consciously, so that in this regard problem solving ability is created and one's psychological capacity for successful passing of critical conditions and mental crises boosts (Farokhzadian, 2012). According to Lazarus and Folkman, coping refers to the process of demand management (external or internal). They believe that coping includes efforts of mental action to manage and control environmental, internal demands and relevant conflicts (Aslani, 2014). The coping skills to life changes and relevant tensions of these changes are different in people based on different condition. Coping skills are a set of cognitive and behavioral efforts made to master, tolerate, or reduce stressful conditions (Samuei, 2006).

One of the coping skills, ignored by most people, is useful application of supportive systems (i.e. friends, 
relatives). These systems help by various methods to cope up with stressful events of life. Thus, you should evaluate your supportive systems and learn how these systems can be useful. Also, you can think about an effective supportive system. The research studies have shown that the people with good social support are optimistic to their lives. Other studies have shown that these people have good supportive systems to cope up with depression and adjustment with supportive systems and they might be predisposed to diseases physiological stress by a lower chance (Aslani, 2014). Social development is one of the concepts with close relationship with the life style of people in a society and its objective dimensions mostly is related to increase of public life level via creating good conditions in poverty eradication, nutrition, health, employment, and training and leisure time. Thus, social development attempts to improve social condition of people in a society and to fulfill such improvement, the extra behavioral models are changed and a good belief and ideal is considered to respond to the social problems (Panahi, 2014).

Adjustment is a logical behavior of health and power, as a person is adapted to new situations and inexperienced conditions, gains high power and self-confidence (Lotfi, 2011). In adjustment, not only a person can adapt himself with surrounding environment, he also can change the environment conditions for his own benefits. Indeed, adjustment is infinite interaction as a person can change himself or the surrounding environment for a better life. Adjustment is a road to perfection by facing with different views and trying to eliminate it. Thus, we should not fear of different views and ask for mutual understanding by any means. Adjustment is meaningful in different views, tastes and opinions in life (Mousavi et al., 2011).

Thus, this study attempts to evaluate the relationship of coping skills with social maturity and adjustment of first of high school girls in district 1 of education Department of Tehran city. The main question is whether coping skills can predict social maturity and adjustment.

\section{Literature Review}

Lyrakos (2012) performed a wide meta-analysis "effectiveness of stress with coping skills in Maastricht University. The result showed that school programs were effective on stress management with coping skills to reduce stress symptoms in children and adolescents. Dadsetan et al. (2007) evaluated the adjustment of adolescents and their perception of the relationship with parents and friends. The results showed that the adolescents, who experience good relations with their parents qualitatively, had better adjustment compared to those who had little relationship quantitatively. The findings of this study showed that consciousness role is raised as (one's tendency to be orderly, sturdiness, thinking about situation, reliability and autonomy) and it acts as protection factor against stress to prevent its effect on selection of coping skills. Those people with high consciousness apply problem-focused coping method.

Huczynski \& Buchanan (2001) stated that adjustment processes were formed in useful social communication and socialization and learning courage skills increased adjustment (Masaebi, 2008). Some scholars believe that total performance can provide high adjustment in serious changes and this adjustment is distinguished from passive adjustment (Mansur \& Dadsetan, 1996). He believes that the first condition of healthy personality is receiving unconditional positive regard and norms can be internalized in this way. A mother can reject some specific behaviors without considering any condition for love and affection and in this way the child can accept the unsuitable behaviors (Masaebi, 2008).

Jones (1977) considers the skills of social maturity as including communication skills, feelings, aggression, skills of stress and planning. Also, we can refer to mentioned skills as verbal, non-verbal skills, trading, social tradition, identification of others rights, deterministic behavior, acknowledgement of self and others, demand and rejection of illogical demands, blame and accepting critics, skill of asking private questions, anger control, dealing with humiliation, aggression and self-expression (Fathi, 2003).

Lazarus (2006) is one of the most effective stress coping skills and most of the studies are based on Lazarus and Folkman model. In this view, not only coping is equal to problem solving, it is based on a person, environment and interaction methods in threatening situations. Lazarus and Folkman (1984) divided stressful situation coping methods into problem-focused and emotion-focused. Problem-focused skills were active problem solving methods to cope up with a person and environment (Compas et al., 2011).

Samuei (2005) stated that coping as a strong factor predicted stressful situation and was affected by personality features of people and resources. Also, the type of skill people choose to cope up with stress is based on personal and social resources. Personal resources include relatively fixed personality traits and their cognitive features as forming the evaluation of situation and coping process. 


\section{Methodology}

This study is a correlation design. The study population is all the female first high school grade students which is 4000. The sample is selected by Krejcie \& Morgan Table which determines 380 of these students. The samples are selected by multi-stage random sampling method. In this study, coping skills are predictor variables and social maturity and adjustment are considered as criterion variable. For data collection, Lazarus coping skills, social maturity of Vineland and adjustment inventory of Bell are used (Sparrow et al., 2005).

\subsection{Lazarus Coping Skill Inventory}

This inventory contains 66 items. It has eight subscales: direct confrontation, distancing, self-control, seeking social support, accepting responsibility, evasion and avoidance, solving planned problems and positive reevaluation. There are 16 distractors in the study and other 50 terms evaluate coping skill method. Cronbach's alpha coefficient of subscales is reported as: Subscale of direct confrontation $=0.70$, distancing subscale $=0.61$, self-control subscale $=0.70$, subscale of seeking social support $=0.76$, subscale accept responsibility $=0.66$, subscale of evasion - avoidance $=0.72$, subscale of planned problem solving $=0.67$ and subscale of positive reevaluation $=0.79$, where these values reflect the desired reliability of the test. In a study performed by Vahedi on 763 male and female students in second and third of high school in Tehran public high schools, the reliability of the Coping skills using internal consistency methods (Cronbach's alpha) was estimated 0.80 .

\subsection{Vineland Social Maturity Survey}

This scale is a development scale measuring one's ability to meet his practical needs and accept responsibility. This scale includes 117 items divided into 1-year groups. Information required is gathered not via test conditions, but through interviews with people aware about the subjects or self-test. Vineland scale was normed on 620 people, including 10 males and 10 females in each age group from birth to age 30.In this sample, the number of people in each of age groups were low and as the subjects were of average class, we cannot consider such sample as the entire population. The reliability coefficient with test re-test of 123 people was 0.92 . The test re-test was from 1 to 9 months and it was translated and normed in by Okhovat and Daneshmand (1978).

\subsection{Bell Adjustment Inventory}

This survey was written in Bell (1961). It includes 160 items. Validity of this questionnaire is standardized in Iran by Delavar (2006). The validity of questionnaire is obtained by two ways. At first, among high schools of district 7, two high schools were selected and of selected schools of each level (seventh, eighths, ninth), two grades were selected. The students were at the age of 14-16 years old. In data analysis, descriptive and inferential statistics, Pearson correlation coefficient and regression analysis were analyzed and the analyses were performed by SPSS software.

\section{Results}

According to the findings, $24 \%$ of subjects were in seventh grade, $38 \%$ eighths grade, $38 \%$ ninth grade. Table 1 shows descriptive indices of study variables.

As shown in Table 2, there is a positive and significant association between problem-focused coping skills and social growth, home adjustment and health adjustment and there is a negative and significant association with social adjustment. Also, emotion-focused coping skills have negative and significant association with social growth and social adjustment $(\mathrm{P}<0.05)$. As we investigate the relationship between coping skills (problem-focused and emotion-focused) as predictor variables with social growth and adjustment (criterion variable), to test the hypotheses (we try to compute correlation of more than two variables), regression statistical method is used. Three basic assumptions of regression are normality of data, Durbin-Watson test to evaluate the independence of errors and co-linearity test with tolerance coefficient and variance inflation factor. To evaluate normality of distribution of variables in population, Kolmogorov-Smirnov test is used. The results of Table 3 show that statistical distribution of all variables is normal.

Hypothesis 1: Coping skills can predict social maturity.

As shown in Table 4, numerical value of Durbin-Watson (1.5) indicates the independence of errors and numerical values of tolerance test (1) and variance inflation factor (1) show that there is no co-linearity between predictive variables. As shown in the Table, problem-focused skills explain $10 \%$ of common variance with social maturity. Thus, the hypothesis is supported and we can say coping skills can predict social maturity. 
Table 1. Descriptive indices

\begin{tabular}{lllll}
\hline Max & Min & SD & Mean & Variable \\
\hline 59 & 9 & 9.1 & 35.9 & Problem-focused skills \\
57 & 11 & 8.3 & 36.6 & Emotion-focused skills \\
45 & 18 & 5.7 & 32.8 & Social maturity \\
26 & 1 & 4.8 & 10.2 & Social adjustment \\
31 & 1 & 6.1 & 13.8 & Emotional adjustment \\
39 & 1 & 8.3 & 13.2 & Health adjustment \\
39 & 1 & 9.1 & 15.6 & Home adjustment \\
135 & 4 & 15.1 & 52.8 & Total adjustment \\
\hline
\end{tabular}

Table 2. Correlation coefficients between the variables

\begin{tabular}{lllllll}
\hline $\begin{array}{l}\text { Social } \\
\text { adjustment }\end{array}$ & $\begin{array}{l}\text { Emotional } \\
\text { adjustment }\end{array}$ & $\begin{array}{l}\text { Health } \\
\text { adjustment }\end{array}$ & $\begin{array}{l}\text { Home } \\
\text { adjustment }\end{array}$ & $\begin{array}{l}\text { Social } \\
\text { growth }\end{array}$ & Variable & \\
\hline-0.11 & 0.06 & 0.12 & 0.11 & 0.10 & $\begin{array}{l}\text { Correlation } \\
\text { coefficient }\end{array}$ & $\begin{array}{l}\text { Problem-focused } \\
\text { skills }\end{array}$ \\
-0.02 & 0.24 & 0.01 & 0.02 & 0.02 & $\begin{array}{l}\text { Significance } \\
\text { level }\end{array}$ & $\begin{array}{l}\text { Correlation } \\
\text { coefficient } \\
-0.09\end{array}$ \\
-0.02 & -0.05 & -0.04 & -0.09 & $\begin{array}{l}\text { Emotion-focused } \\
\text { skills }\end{array}$ \\
\hline
\end{tabular}

Table 3. The results of Kolmogorov-Smirnov test to evaluate normality of distribution of variables ( $\operatorname{sig}>0.05)$

\begin{tabular}{llll}
\hline Significance level & Kolmogorov-Smirnov Z & $\mathrm{N}$ & Variable \\
\hline 0.06 & 1.3 & 370 & Problem-focused skills \\
0.2 & 1.1 & 370 & Emotion-focused skills \\
0.4 & 0.8 & 370 & Social maturity \\
0.06 & 1.5 & 370 & Social adjustment \\
0.4 & 0.8 & 370 & Emotional adjustment \\
0.2 & 1.1 & 370 & Health adjustment \\
0.39 & 0.9 & 370 & Home adjustment \\
0.2 & 0.7 & 370 & Total adjustment \\
\hline
\end{tabular}

Table 4. Summary of regression model of social maturity prediction

\begin{tabular}{|c|c|c|c|c|c|c|c|}
\hline \multicolumn{2}{|c|}{ Co-linearity } & \multirow{2}{*}{ Durbin-Watson } & \multirow{2}{*}{$\begin{array}{l}\text { Standard } \\
\text { regression } \\
\text { error }\end{array}$} & \multirow{2}{*}{$\begin{array}{l}\text { Squared } \\
\text { correlation } \\
\text { coefficient }\end{array}$} & \multirow{2}{*}{$\mathrm{R} 2$} & \multirow{2}{*}{$\begin{array}{l}\text { Correlation } \\
\text { coefficient R }\end{array}$} & \multirow{2}{*}{ Model } \\
\hline VIF & Tolerance & & & & & & \\
\hline 1 & 1 & 1.5 & 5.7 & 0.09 & 0.10 & 0.11 & $\begin{array}{l}\text { Problem-focused } \\
\text { skills }\end{array}$ \\
\hline
\end{tabular}

Table 5. Coefficients of variables (regression) in social maturity

\begin{tabular}{llllll}
\hline $\begin{array}{l}\text { Significance } \\
\text { level }\end{array}$ & $\mathrm{t}$ & $\begin{array}{l}\text { Beta standardized } \\
\text { coefficient }\end{array}$ & $\begin{array}{l}\text { Standard error of Beta } \\
\text { coefficient }\end{array}$ & Beta & Variable \\
\hline 0.000 & 24.9 & --- & 1.2 & 30.5 & Constant \\
0.04 & 1.9 & 0.10 & 0.03 & $0.06 \begin{array}{l}\text { Problem-focused coping } \\
\text { skills }\end{array}$ \\
\hline
\end{tabular}


Table 5 shows that standardized Beta coefficients of problem-focused coping skills are 0.06 and significant. By this Table, we can consider the following model for social maturity prediction.

Estimation of social maturity $=($ Score of problem-focused coping skills $) \times 0.06+(30.5)$

Hypothesis 2: Coping skills can predict adjustment.

Table 6. Summary of regression model of adjustment prediction

\begin{tabular}{llllllll}
\hline $\begin{array}{l}\text { Co-linearity } \\
\text { VIF }\end{array}$ & Tolerance & Durbin-Watson & $\begin{array}{l}\text { Standard } \\
\text { regression } \\
\text { error }\end{array}$ & $\begin{array}{l}\text { Squared } \\
\text { correlation } \\
\text { coefficient }\end{array}$ & R2 & $\begin{array}{l}\text { Correlation } \\
\text { coefficient R }\end{array}$ & Model \\
\hline 1 & 1 & 1.5 & 15 & 0.008 & 0.11 & 0.11 & $\begin{array}{l}\text { Problem-focused } \\
\text { skills }\end{array}$ \\
\hline
\end{tabular}

As shown in Table 6, numerical value of Durbin-Watson (1.5) indicates the independence of errors and numerical values of tolerance test (1) and variance inflation factor (1) show that there is no co-linearity between predictive variables. As shown in the Table, problem-focused skills explain $11 \%$ of common variance with adjustment. Thus, the hypothesis is supported and we can say coping skills can predict adjustment.

Table 7. Coefficients of variables (regression) in adjustment

\begin{tabular}{|c|c|c|c|c|c|c|}
\hline $\begin{array}{l}\text { Significance } \\
\text { level }\end{array}$ & $\mathrm{t}$ & $\begin{array}{l}\text { Beta standardized } \\
\text { coefficient }\end{array}$ & $\begin{array}{l}\text { Standard error of } \\
\text { Beta coefficient }\end{array}$ & Beta & Variable & Model \\
\hline 0.000 & 13.2 & --- & 3.2 & 42.6 & Constant & \\
\hline 0.04 & 2.1 & 0.11 & 0.09 & 0.18 & $\begin{array}{l}\text { Problem-focused } \\
\text { coping skills }\end{array}$ & 1 \\
\hline
\end{tabular}

Table 7 shows that standardized Beta coefficients of problem-focused coping skills are 0.18 and significant. By this Table, we can consider the following model for adjustment prediction.

Estimation of adjustment $=($ Score of problem-focused coping skills $) \times 0.18+(42.6)$ [Model]

\section{Conclusion and Discussion}

This study aims to evaluate the relationship between coping skills and social maturity and adjustment of female students of first grade of high school in district 7 of education department of Tehran city. The sample size was 380 and they were all evaluated (high schools of district 7 of education department). The coping skills scale of Lazarus \& Folkman with 66 items, Vineland social maturity with 117 items and Bell adjustment scale with 160 items were used in order to collect the data. Then the data were analyzed by SPSS software. Testing the main hypothesis of study shows that coping skills predicted social maturity and coping skills could predict adjustment.

Coping skills predict social maturity and adjustment among female students. This result is consistent with the results of Aslani (2014) regarding coping skills and the researches done by Fathi (2003) regarding social maturity. The results of their studies showed that coping skill predict social growth and our hypothesis is also consistent in terms of prediction of coping skill with social maturity (Aslani, 2014).

Farokhzadian (2012) in their study regarding coping skill and Panahi (2014) and Mousavi et al. (2011) were consistent regarding adjustment. They showed that coping skills predict adjustment and this hypothesis was consistent in terms of prediction of coping skill with adjustment (Farokhzadian, 2012). Adjustment is affected by social, mental and biological factors as negative emotions of social problems or physical problems by creating psychological problems and can disturb this process (Lev-Wiesel et al., 2006). In recent years, neural-mental system theory relevant with motivation and emotion, personality and psychopathology have received much attention (Carver \& Eysenck., 2000).

The results of study show that training coping skills with social maturity and adjustment increase skills of students with their surrounding environment. Also, we can study the evaluation of these skills with emotions as depression, anger, etc.

\section{Recommendations for Further Studies}

- Comprehensiveness of study population to achieve tangible results. 
- Using intervention method and effectiveness in further studies.

- Using qualitative and interview methods with the same title to achieve exact results namely among adolescents.

- Using researchers to evaluate the coping skills variable with suitable variables in adolescents as friendship of girls and boys, escaping from home, etc.

- In this study, adolescents are used for research; it is recommended that this study is conducted on different population, age and different districts.

\section{References}

Aslani, B. (2014). Effectiveness of social skills based on cognitive behavioral approach in changing coping skills of guidance school students. MA thesis. Allame Tabatabayi University. Department of psychology and educational sciences.

Bell, W. E., \& Bloom, A. L. (1961). Optically driven spin precession. Physical Review Letters, 6(6), 280. http://dx.doi.org/10.1103/PhysRevLett.6.280

Carver, C., \& Eysenck, B. (2000) Assessment coping skills and theoretical based approach. Journal of personality and social psychology.

Compas, B. E., Connor-Smith, J. K., Saltzman, H., Thomsen, A. H., \& Wadsworth, M. E. (2001). Coping with stress during childhood and adolescence: problems, progress, and potential in theory and research. Psychological bulletin, 127(1), 87. http://dx.doi.org/10.1037/0033-2909.127.1.87

Dadsetan, P., Ahmad, A., Marzie, H., \& Asgari, A. (2007). Validation, normalization and determination of factor structure of coping skills of adolescents. Journal of Iranian psychologists, 11.

Delavar, A. (2006). Research methods in psychology and education. Tehran: Virayesh.

Farokhzadian, A. A. (2012). Effectiveness of problem-focused skill on the change of coping skills. Increasing self-efficiency and reduction of identity crisis with mediation of identity status in adolescents. MA thesis. Science and culture department, Humanistic University.

Fathi, F. (2003). The investigation of the effect of two group methods of training social skills and cognition therapy on increase of self-esteem of girl students of high schools. MA thesis. Allame Tabatabayi University.

Hall, G. S. (1916). Adolescence: Its psychology and its relations to physiology, anthropology, sociology, sex, crime, religion and education, 2. D. Appleton. http://dx.doi.org/10.1037/13851-008

Huczynski, A., \& Buchanan, D. (2001). Organizational Behavior: An Introductory Text (Instructor's Manual). Financial Times/Prentice Hall.

Jones, F. H. (1977). The Rochester Adaptive Behavior Inventory: A parallel series of instruments for assessing social competence during early and middle childhood and adolescence. In The origins and course of psychopathology (pp. 249-281). Springer US. http://dx.doi.org/10.1007/978-1-4684-2355-6_11

Lazarus, R. S. (2006). Stress and Emotion: A New Synthesis (2nd ed.). New York: Springer Publishing.

Lazarus, R. S., \& Folkman, S. (1984). Stress, Appraisal, and Coping. New York: Springer Publishing Company.

Lev-Wiesel, R., Nuttman-Shwartz, O., \& Sternberg, R. (2006). Peer rejection during adolescence: Psychological long-term affects a brief report. J Loss Trauma, 11, 131-142. http://dx.doi.org/10.1080/15325020500409200

Lotfabadi, H. (2011). Development psychology (2). Adolescence, Youth and adulthood (12th ed.). SAMT publication.

Lyrakos, D. G. (2012). The impact of stress, social support, self-efficacy and coping on university students, a multicultural European study. Psychology, 3(2), 143. http://dx.doi.org/10.4236/psych.2012.32022

Mansur, M., \& Dadsetan, P. (1996). Genetic psychology, 2. Tehran: Darya.

Masaebi, A. (2008). The effect of training anger control skills on aggression and social adjustment of male students aged 12-13 years old. MA thesis. Department of psychology and educational sciences. Allame Tabatabayi University.

Mousavi, M., Raeesi, M., \& Asgharnejad, F. (2013). The relationship between emotional intelligence and academic adjustment in pre-university female students of Tehran University of Medical Sciences Journal, 14(2). 
Okhovat, V., \& Daneshmand, L. (1978). Psychology Assessment. Tehran: University of Tehran.

Panahi, R. (2014). The mediating role of social growth among learning styles and academic adjustment. MA thesis. Islamic Azad University of Marvdasht branch. Department of educational sciences and psychology.

Samuei, R. (2006). The stress coping model in self-introducing addicts of addiction centers of Isfahan. Thought and behavior, 44.

Shoarinejad, A. (2009). Psychology of development (19th ed.). Tehran. Information Journal.

Sparrow, S. S., Balla, D. A., \& Cicchetti, D. V. (2005). Vineland-II: Vineland adaptive behavior scales; [VABS]; Survey Forms manual; a revision of the Vineland Social Maturity Scale. Pearson Assessments.

\section{Copyrights}

Copyright for this article is retained by the author(s), with first publication rights granted to the journal.

This is an open-access article distributed under the terms and conditions of the Creative Commons Attribution license (http://creativecommons.org/licenses/by/3.0/). 